\title{
Relações de gênero e educação: crítica aos projetos de lei "Escola Sem Partido"
}

Gender Relations and Education: Criticism of the Bills "School Without Political Party"

Ana Paula Hilgert de Souza*

\section{Resumo}

Na conjuntura política atual, em que a garantia de um Estado laico encontra-se ameaçada por interesses políticos de determinados grupos de legisladores, a educação vem sendo cerceada de princípios básicos garantidos pela Lei de Diretrizes e Bases (no 9.394/96), tais como liberdade de aprender, ensinar, pesquisar e divulgar a cultura, o pensamento, a arte e o saber; pluralismo de ideias e de concepções pedagógicas; respeito à liberdade e apreço à tolerância. $\mathrm{O}$ artigo discute o modo como esses três princípios vêm sendo negligenciados por concepções político-religiosas mediante estratégias políticas de determinados grupos que levantam hoje a bandeira de um ideal propagado como "Escola Sem Partido". Também reflete sobre o modo como a crítica aos conteúdos escolares que versam sobre a identidade de gênero e a sexualidade está atrelada aos objetivos dos adeptos do Movimento Escola Sem Partido (MESP).

Palavras-chave: Movimento Escola Sem Partido; doutrinação marxista; ideologia de gênero.

\section{Abstract}

In the current political conjuncture, where the guarantee of a secular state is threatened by the political interests of certain groups of legislators, education has been curtailed by basic principles guaranteed by the Law of Guidelines and Bases (9.394/96), such as freedom to learn, teach, research and disseminate culture, thought, art and knowledge; pluralism of ideas and pedagogical conceptions; and respect for freedom and appreciation of tolerance. The article discusses how these three principles have been neglected by political-religious conceptions through political strategies of certain groups that nowadays raise the banner of an ideal propagated as "school without political party". The article also discusses how the criticism of school content dealing with gender identity and sexuality is linked to the objectives of the "School without Political Party” Movement (MESP) supporters.

Keywords: "School without Political Party" movement; Marxist indoctrination; gender ideology.

\footnotetext{
* Doutoranda pela Universidade Federal da Grande Dourados (UFGD). Dourados, MS, Brasil. paulahilgert.ufgd@gmail.com
} 
É lugar-comum entre os estudiosos de gênero, ou mesmo entre simpatizantes do movimento feminista, a constatação de que grande parte das pessoas que se posicionam favoráveis ao que foi equivocadamente conhecido como "ideologia de gênero" não sabem como fundamentar seus argumentos em proposições teóricas sólidas. Tais opiniões revelam um modo de ler o mundo ainda retrógrado, em que as concepções de sociedade permanecem fortemente influenciadas pelas noções da religião cristã.

Posteriormente ao movimento reformista religioso do século XVI, iniciado com Lutero na Alemanha, gerou-se um número crescente de denominações religiosas de cunho protestante, e desse movimento surgiu, já no século XX, um novo formato de Igreja e das relações que se estabelecem entre elas e seus fiéis. ${ }^{1}$ Ainda que, atualmente, a Igreja católica exerça grande poder e influência na dinâmica da sociedade, não precisamos ir muito longe para perceber que os poderes legislativos municipais e estaduais e o Congresso Nacional estão ocupados pela chamada "bancada evangélica", de caráter conservador e bandeira progressista.

Sob influência desse grupo ocorreu a retirada de discussões sobre identidade de gênero e sexualidade nas escolas, temas que apesar de comporem o Plano Nacional de Educação (PNE 2014), foram vetados em 2015. Esse fato promoveu naquele ano um intenso debate político no Brasil que permanece na pauta, tanto de educadores, como de movimentos sociais e segmentos políticos. Atrelada a esses vetos encontra-se a negação de uma formação política crítica, por meio do Projeto de Lei 867/15 - "Escola Sem Partido", pretendida por determinados agentes políticos e defendida por significativa parcela da sociedade civil. ${ }^{2}$ Defendo que esse embate resulta de posições políticas distintas, na medida em que, ao cercear a liberdade de expressão no processo de ensino, utiliza-se de uma cortina de neutralidade que encobre a incansável tentativa de manter os privilégios patriarcalistas decorrentes desde o processo colonizador-civilizatório.

Neste artigo, pretendo desenvolver uma reflexão que sirva, se não como análise crítica ${ }^{3}$ das ideias e intenções desses projetos, como reflexão sobre a rejeição aos estudos de gênero, por ferir diretamente o direito à igualdade das mulheres e o direito à diversidade.

Escritos sobre a educação nacional não podem ser desvinculados de uma sutil observação da Lei de Diretrizes e Bases da Educação Nacional (LDB), 
sancionada em 1996. Atenho-me, entretanto, a destacar que a referida lei tem sua trajetória de elaboração inserida numa conjuntura de redemocratização do país. Assim, a LDB traz em seu texto 11 princípios básicos para a educação, dos quais atento para três:

II - liberdade de aprender, ensinar, pesquisar e divulgar a cultura, o pensamento, a arte e o saber;

III - pluralismo de ideias e de concepções pedagógicas;

IV - respeito à liberdade e apreço à tolerância.

Esses três princípios vêm sendo negligenciados por concepções político-religiosas mediante estratégias políticas de determinados grupos que levantam hoje a bandeira de um ideal propagado como "Escola Sem Partido". ${ }^{4}$ É válido ressaltar que as expressões diversas de engajamento filosófico-político atuam como manifestação de opiniões e não como imposições, ${ }^{5}$ o que resulta, pelo menos, no profícuo debate acerca da natureza política dos homens, noção existente desde a antiguidade clássica.

A Figura 1 apresenta uma imagem que vem sendo veiculada pela internet desde março de 2015, momento em que algumas campanhas contrárias ao governo de Dilma Rousseff promoveram manifestações pelo país. A imagem incomoda pela tamanha incoerência de sus mensagem, porque o rompante doutrinador se apresenta de modo inverso ao que nela está inscrito e deixa subentendida a imposição de concepções dadas como verdades absolutas. ${ }^{6}$

Constata-se, na imagem, que os três princípios da LDB (1996) citados anteriormente estão sendo molestados com base em um projeto de lei respaldado por fundamentalismos - o religioso e o de mercado - que tem impedido o debate didático-científico. A expressão "fundamentalismo de mercado" vai ao encontro das teorias neoliberais para a educação, que cada vez mais a percebem como mercadoria.

Nesse sentido, os estudos de Pablo Gentili mostram-se relevantes ao inferir que existem intenções de despolitização da educação na doutrina neoliberal, bem como necessidades de ressignificar a educação como mercadoria para "garantir, assim, o triunfo de suas estratégias mercantilizantes e o necessário consenso em torno delas" (Gentili; Silva, 2001, p.244). A teoria da ação (libertadora) freiriana vê o processo de ensino como dialógico, que entende o 
Figura 1 - Manifestantes seguram faixa com mensagem contrária à pedagogia crítica de Paulo Freire

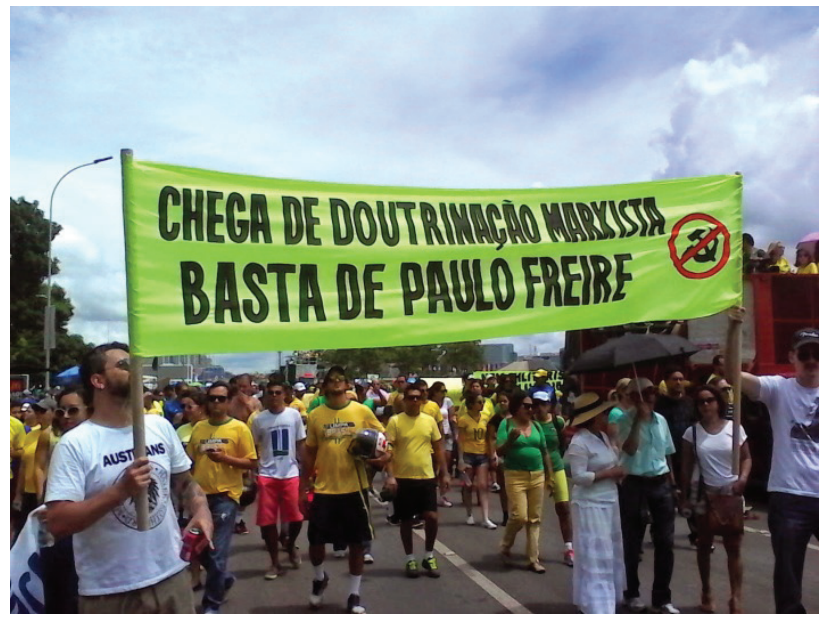

Fonte: http://www.planocritico.com/fora-de-plano-14-chega-dedoutrinacao-marxista-basta-de-paulo-freire/

próprio ser (aluno) como comunicação. Freire (2014, p.173) aponta que negar a intercomunicação é temer a liberdade. Assim, entende-se que refutar uma educação com base no diálogo significa reduzir os alunos a meras coisas, sem sentido na existência.

O filósofo e pedagogo Paulo Freire (1921-1997), expressão da pedagogia crítica, estudado mundialmente, legou uma rica produção teórica que atualmente vem sendo alvo de determinados grupos sociopolíticos, apontado como pai da "doutrinação marxista" nas escolas do Brasil. Qual seria, portanto, o real perigo da teoria de Freire? Em 1968 - ano da primeira edição de Pedagogia do oprimido - esse pensador escreveu que

críticos seremos se vivermos a plenitude da práxis ... se nossa ação involucra uma crítica reflexão que, organizando cada vez o pensar, nos leva a superar um conhecimento estritamente ingênuo da realidade. Este [pensamento] precisa alcançar um nível superior, com que os homens cheguem à razão da realidade. Mas isso exige um pensar constante que não pode ser negado às massas populares, se o objetivo visado é a libertação. (Freire, 2014 p.176, grifos meus) 
A disseminação da foto apresentada na Figura 1 resultou numa ampla defesa à pedagogia libertadora e crítica de Paulo Freire, que entende a impossibilidade da neutralidade em educação. Observa-se, desse modo, que

A chave para compreendermos a acusação de "doutrinador marxista" contra Paulo Freire não está em sua obra. Encontra-se na mentalidade daqueles que produziram a mensagem, em sua compreensão estreita do que é educação e do que é ensinar. Essas pessoas acreditam piamente no mito da neutralidade da ação docente, segundo o qual o professor não tem cara, não tem lado, não toma partido, não pensa nem intervém de modo transformador na realidade social. Para elas, o professor deve estar unicamente comprometido com a sagrada missão de transmitir conteúdos anonimamente escolhidos, aparentemente desinteressados e oficialmente listados. Conteúdos supostamente eficazes, pragmáticos e destinados a aplacar a sanha competitiva por boas posições escolares e universitárias que tenham o condão de assegurar condições ideais de disputa nas escassas oportunidades de uma sociedade excludente. Na verdade, o acusador grita contra o espelho. É ele, e não Paulo Freire, quem prega a doutrinação. Qual? Diríamos, sem medo de errar: a "doutrinação bancária", aquela que transfere "ao outro, tomado como paciente de seu pensar, a inteligibilidade das coisas, dos fatos, dos conceitos". (Cavalcante; Mattos, 2016, s.p.)

Atrelada aos objetivos dos adeptos do Movimento Escola Sem Partido (MESP) está a crítica aos conteúdos escolares que versam sobre a identidade de gênero e a sexualidade. Assim, considera-se que "Escola Sem Partido" e "Ideologia de gênero" são temáticas da atual pauta política de um grupo específico da sociedade brasileira.

Num horizonte epistemológico, a chamada "doutrinação marxista" se funde ao discurso sobre gênero nas propostas conservadoras dos seus críticos, passando a compor uma disputa simbólica travada entre a autoridade familiar, fomentada nos moldes de patriarcalismo, e o direito ao saber, ao conhecimento e ao próprio sistema educacional brasileiro, que tem respaldo na Constituição Federal.

O discurso da família que justifica no campo da moral (religiosa) sua intervenção na escola e mais diretamente na prática pedagógica docente, na percepção do MESP valida até mesmo o direito de notificar extrajudicialmente profissionais da educação. Tal notificação, segundo o movimento, atuaria 
como um serviço de utilidade pública. O site do grupo oferece um modelo de notificação que "pode ser adaptável de acordo com a imaginação dos pais" dos alunos. Luis Miguel (2016) indica que "a campanha pelas notificações extrajudiciais contra escolas e contra docentes surgiu às margens do MESP, na direita católica, tendo como iniciador o procurador Guilherme Schelb” (Miguel, 2016, p.602).

Especificamente no contexto do que foi pejorativamente enunciado no Brasil como "ideologia de gênero", entende-se que discutir e ensinar relações de gênero na escola, permitindo a reflexão e a intercomunicação, possibilitaria, em primeiro lugar, desconstruir o gênero como uma imposição ideológica e lançar um olhar que torne possível a compreensão dos papéis atribuídos aos seres ao longo da história.

Essa é, indubitavelmente, uma das razões que causam temor entre os agentes políticos articuladores do "Escola Sem Partido" - e usam o véu do conservadorismo -, porque tal entendimento produz uma série de reflexões, sobretudo as que observam a cultura como construção a partir de convenções sociais produzidas e ressignificadas constantemente.

O discurso conservador insiste na tese de que os papéis sociais dos homens e das mulheres são reflexos da dualidade sexual, da diferença biológica, e nessa insistência ganha corpo a atuação política, haja vista a expressividade de parlamentares cristãos no Congresso. Essa leitura, ao acusar certas práticas pedagógicas de "doutrinação marxista" (freiriana), é carregada de preceitos que reforçam os estereótipos, as desigualdades, e escondem a realidade.

Inúmeros projetos de lei de âmbito municipal surgiram após a retomada daquele de autoria de Miguel Nagib, que tem sua origem em 2004, mas que foi retomado com vigor a partir de 2010. Um tenebroso risco se aproxima caso ocorra a instituição desmedida desses projetos que têm repercutido nacionalmente, fundamentados em um discurso que tenta desesperadamente inviabilizar a produção do conhecimento mediante formação crítica e reflexiva sobre relações de gênero. Com as conviç̧ões infundadas de uma moral religiosa, estaria sendo proposto o silenciamento de discussões que buscam também questionar os papéis atribuídos à mulher ao longo da história. ${ }^{7}$

Em abril de 2017, outro episódio também confluiu com interesses anteriores, quando houve a retirada dos conceitos de identidade de gênero e sexualidade do Plano Nacional de Educação, sancionado em 2014, gerando debates 
das políticas públicas para a educação nacional. O Ministério da Educação retirou do documento Base Nacional Comum Curricular (BNCC) trechos que visavam promover a igualdade e o direito à diversidade. Em matéria ao site EBC Agência Brasil a jornalista Mariana Tokarnia (2017) escreve que "a retirada do termo orientação sexual e das discussões sobre questões de gênero da BNCC era demanda de setores conservadores do Congresso Nacional”. A reação não tardou a chegar, felizmente. Procurarei demonstrar, com percepções básicas dos estudos de gênero, que tal medida configura-se no cenário educacional como um retrocesso, compartilhando das impressões de Daniel Cara e de inúmeros intelectuais e trabalhadores da educação ao inferir que

É injustificável a retirada [do termo orientação sexual e da discussão sobre questões de gênero do plano Nacional de Educação - PNE]. A escola tem missão de garantir que na sociedade todos respeitem todas as formas de identidade. Não colocar essa questão na BNCC [Base Nacional Comum Curricular] significa que não vão refletir sobre um país que é machista, misógino, homofóbico. É um recuo grave. (Cara, 2017, s.p., apud Tokarnia, 2017, s.p., grifos meus)

Defende-se que a "razão" religiosa não deve sobressair ao direito de se conhecer os conteúdos científicos apresentados pela educação escolar, e isso vem, neste momento histórico, cobrar dos intelectuais e dos educadores comprometidos com uma educação democrática um posicionamento nas lutas simbólicas e nas relações de poder travadas no campo da política e da educação nacionais.

Nota-se que duas vias de pensamento teórico serviram de base para o Movimento Escola Sem Partido (MESP): uma delas, discutida em texto de Luiz Felipe Miguel, defende que os discursos reacionários da ala conservadora na política brasileira provêm da ideologia ultraliberal libertariana, ${ }^{8}$ influente nos Estados Unidos, que pretende assumir um projeto progressista hegemônico na conjuntura política e social atual. $\mathrm{Na}$ agenda progressista da conjuntura atual da política brasileira, a esfera da vida privada ocupa papel de destaque. Aliados das concepções neoliberais de redirecionamento das funções do Estado no que tange especialmente à economia nacional, grupos de legisladores com aporte num fundamentalismo religioso que "se define pela percepção de que há uma verdade revelada que anula qualquer possibilidade de debate" (Miguel, 2016, p.593) têm assumido um papel nas políticas públicas em educação que 
coloca em xeque toda uma trajetória de conquistas na formação de milhares de crianças e adolescentes. O mesmo autor ${ }^{9}$ entende que o MESP transferiu a discussão acerca da "doutrinação ideológica" "para um terreno aparentemente 'moral' (em contraposição a 'político') e passou a enquadrá-la nos termos de uma disputa entre escolarização e autoridade da família sobre as crianças" (Miguel, 2016, p.596).

É razoável esclarecer que a expressão "Ideologia de gênero" foi concebida no centro de discursos religiosos num período recente. Em 2012, o uso dessa expressão popularizou-se nos meandros das comunidades cristãs, sobretudo após a publicação, no Brasil, do livro Ideologia de Gênero: neototalitarismo e a morte da família, escrito pelo argentino Jorge Scala. É nessa segunda via de pensamento que setores da sociedade civil se apoiam para negar e atacar as temáticas relacionadas aos estudos de gênero, bem como negar a história das mulheres. Essa pejorativa e equivocada noção de ideologia não reflete a compreensão do que é o gênero, tampouco explica os conhecimentos produzidos por diversas áreas, como antropologia, sociologia e filosofia, entre outras, a respeito dos estudos de gênero. O livro de Jorge Scala, publicado pela editora Katechesis, é incapaz de perceber a genealogia da palavra "gênero" e tampouco os usos que os estudos acadêmicos fazem dela para diferenciar o sexo biológico, a sexualidade e o gênero. Os principais equívocos do autor resultam de percebê-los sob uma só acepção. Outra afirmação discutível de Scala é a de que a ideologia de gênero é uma pseudoantropologia feminista, lamentavelmente se opondo a compreender que diversas áreas do conhecimento produziram sólidos estudos, principalmente na segunda metade do século XX.

Para aquele autor, questionar os papéis atribuídos às mulheres na sociedade não teria como finalidade a reflexão e o conhecimento de como as mulheres foram excluídas e marginalizadas ao longo da história. Ele se apoia exclusivamente na premissa de que esse questionamento, que é legítimo, serviria para as feministas atingirem seu objetivo de promover "uma reengenharia social planetária". Essa nova organização teria na linguagem a força suficiente para produzir uma lavagem cerebral no mundo e dar poder às mulheres que têm como objetivo final construir um novo mundo do gênero (Scala, 2011, p.62), e esse mundo, no campo da política, teria como base um regime totalitário, governado pelas mulheres. ${ }^{10}$ 
Trata-se, certamente, de uma aspiração demasiadamente fantasiosa, que as intelectuais e as feministas da militância estão longe de idealizar. Jorge Scala, ao ironizar a assertiva de que o gênero é o sexo construído socialmente - sem se dar conta da complexidade que os estudos de gênero teorizam - observa o que chamou de postulado ideológico inicial (Scala, 2011, p.54). Mas ele afirma que isso "equivale a não dizer absolutamente nada; é uma das tantas frases sem sentido, que nada significa ... [mas] deve significar alguma coisa porque seria impossível que tanto se tenha escrito sobre o nada mais absoluto" (Scala, 2011, p.55, grifo meu).

O desarranjo de sua argumentação e as afirmações vagas têm servido de fundamentação teórica aos setores conservadores contrários ao debate acerca das relações gênero. Frases como "convite a autodestruição", "opções sexuais desumanizam a pessoa humana", "destruição da família" e "educação para a perversão" estão sendo propagadas por mídias e congressos religiosos.

Apesar dessas afirmações - que carregam traços doutrinadores e ideológicos -, o movimento feminista procura, em primeira instância, dar visibilidade às mulheres e empoderá-las de modo a serem percebidas como sujeitos que não precisam mais de um contrato sexual (cf. Pateman, 1993) para se incluírem na história.

Temas como orientação sexual, ética e saúde, entre outros, foram incluídos nos anos 1990 nos Parâmetros Curriculares Nacionais (PCN) a partir do que ficou conhecido como temas transversais. Uma vez que o trabalho efetivo desses temas parecia, por vezes, inviável, ${ }^{11} \mathrm{o}$ caminho para instruir a temática foi pensado de modo a promover um enfrentamento à resistência e até mesmo a dificuldade da família em discutir sexualidade com os filhos, revelando o quanto o sexo foi historicamente tratado como tabu.

Entretanto, os chamados temas transversais surgem de reuniões e fóruns de educação ocorridos mundialmente e que nortearam a produção dos Parâmetros Curriculares Nacionais ao longo da última década do século XX e a primeira do XXI, especialmente. O "manual" dos PCN para orientação sexual entende que

As manifestações da sexualidade afloram em todas as faixas etárias. Ignorar, ocultar ou reprimir são respostas habituais dadas por profissionais da escola, baseados na ideia de que a sexualidade é assunto para ser lidado apenas pela 
família. Na prática, toda família realiza a educação sexual de suas crianças e jovens, mesmo aquelas que nunca falam abertamente sobre isso. $\mathrm{O}$ comportamento dos pais entre si, na relação com os filhos, no tipo de "cuidados" recomendados, nas expressões, gestos e proibições que estabelecem, são carregados dos valores associados à sexualidade que a criança e o adolescente apreendem. $\mathrm{O}$ fato de a família ter valores conservadores, liberais ou progressistas, professar alguma crença religiosa ou não, e a forma como o faz, determina em grande parte a educação das crianças e jovens. Pode-se afirmar que é no espaço privado, portanto, que a criança recebe com maior intensidade as noções a partir das quais vai construindo e expressando a sua sexualidade. Se as palavras, comportamentos e ações dos pais configuram o primeiro e mais importante modelo da educação sexual das crianças, muitos outros agentes sociais e milhares de estímulos farão parte desse processo. Todas as pessoas com quem convivem - outras crianças, jovens e adultos - ao expressarem sua sexualidade ensinam coisas, transmitem conceitos e ideias, tabus, preconceitos e estereótipos que vão se incorporando à educação sexual. A mídia, nas suas múltiplas manifestações, e com muita força, assume relevante papel, ajudando a moldar visões e comportamentos. Ela veicula imagens eróticas, que estimulam crianças e adolescentes, incrementando a ansiedade e alimentando fantasias sexuais. Também informa, veicula campanhas educativas, que nem sempre são dirigidas e adequadas a esse público. Muitas vezes também moraliza e reforça preconceitos. Ao ser elaborada por crianças e adolescentes, essa mescla de mensagens pode acabar produzindo conceitos e explicações tanto errôneos quanto fantasiosos. A sexualidade no espaço escolar não se inscreve apenas em portas de banheiros, muros e paredes. Ela "invade" a escola por meio das atitudes dos alunos em sala de aula e da convivência social entre eles. Por vezes a escola realiza o pedido, impossível de ser atendido, de que os alunos deixem sua sexualidade fora dela. (Brasil, 1998, p.291-292)

Partilho das proposições dos Parâmetros Curriculares Nacionais ao entender que o tema da sexualidade toma um caráter de urgência porque está em todos os lugares, dentro e fora da escola. Hoje, mais do que em qualquer outra época, a forte utilização de mecanismos da tecnologia como smartphones e tablets demonstra quão rápido pode ser o acesso ao tema da sexualidade sem a interferência dos pais e da própria escola.

Mary Figueiró considera que 
Para poder definir quais temas sociais deveriam ser selecionados como transversais, a equipe responsável pela elaboração dos PCNs estabeleceu que o tema teria que atender aos critérios de urgência social, abrangência nacional, possibilidade de ensino e aprendizagem no ensino fundamental, favorecimento da compreensão da realidade e da participação social. A Educação Sexual pôde ser incluída, então, por atender a todos os critérios acima. $\mathrm{O}$ fator mais decisivo para tal foi, sem dúvida, a urgência social, o que é totalmente válido e fundamentado. Uma coisa fica clara: se não fossem os problemas que a vivência da sexualidade traz para a sociedade, ela não estaria entrando agora no currículo escolar. Ter sido incluída por este critério pode interferir no sentido, para o professor, do ensino das questões da sexualidade. (Figueiró, 2000, s.p.)

Considerado esse caráter de urgência, compreende-se que os estudantes, se cerceados do direito de compreender e aprender orientação sexual na escola e na vida privada, em família, tenderão a desenvolver-se dentro de limites que não são de modo algum positivos, sobretudo porque escamoteiam os perigos atrelados à vivência da atividade sexual na adolescência, tais como gravidez indesejada, doenças sexualmente transmissíveis e mesmo a pedofilia, que hoje ocupa posição alarmante no que se enquadra como crime na internet e em outros espaços de vida dos estudantes.

Compartilhando das acepções de Miguel (2016), de que na conjuntura política e educacional que vivemos é preciso "dessacralizar a família" a fim de expandir a compreensão e superação das desigualdades sociais, percebe-se que a família

é também um lugar de opressão e de violência. A defesa de uma concepção plural de família não pode colocar em segundo plano a ideia de que é necessário proteger, sempre, os direitos individuais dos seus integrantes. E entre estes direitos está o de ter acesso a uma pluralidade de visões de mundo, a fim de ampliar a possibilidade de produção autônoma de suas próprias ideias. (Miguel, 2016, p.605)

Desse modo, a "família tradicional”, ao blindar-se com o escudo do fundamentalismo religioso, passa a negligenciar um direito fundamental da criança que é o devido conhecimento de si e de seu corpo e suas descobertas presentes na adolescência. Assim, assume um papel de instituição social que tem impossibilitado o debate dessa temática tão latente entre os filhos. 
Trago a seguir um trecho de texto publicado em jornal on-line em $2016 \mathrm{e}$ imagens produzidas por integrantes do Movimento Escola Sem Partido (MESP), veiculadas na internet num momento em que afloraram os debates acerca da "necessidade" de neutralidade na educação:

Chega de ficar em silêncio. Precisamos bradar aos quatro cantos que há um lindo cavalo de madeira no pátio da escola. Ele é grande, suntuoso e nada se parece com um espantalho produzido para estabelecer pânico social. Muito pelo contrário. Trata-se de um cavalo magnífico, feito para encantar desavisados professores, coordenadores, gestores e reprogramar crianças. Um cavalo que traz sobre o dorso uma sela cuidadosamente trançada e multicolorida como símbolo das diferentes culturas e da diversidade de gênero. Como um presente de grego, esse Cavalo de Troia chega com nobres intenções: acabar com o preconceito contra os diferentes, construir relações de gênero mais justas e ressignificar as práticas sociais por meio da construção de uma cultura de paz ... Esse magnífico presente que adentra à escola, símbolo da suposta defesa dos direitos humanos, trouxe em seu interior "a maldita e mal dita" ideologia de gênero - expressão usada por um professor de Goiânia (Thiago Cazarim). Mas como os soldados dentro do Cavalo de Troia, essa ideologia se materializa em militantes armados em suas línguas ferinas prontas para acusar, difamar, desrespeitar e difundir o preconceito contra a família tradicional e os religiosos cristãos. Eles estão prontos para agredir verbalmente, e quiçá, fisicamente, quem não idolatra a estátua de madeira que ameaça confundir as identidades de crianças indefesas e inocentes ... A quem desejam enganar os ideólogos de gênero? E quem eles chamam para defendê-los? Justamente Gramsci, Butler, Marx, Beauvoir? Exatamente os militantes assumidos do ideário de gênero? O que é isso? Confissão ou delação premiada? E qual é o prêmio? Destruir a família tradicional ou burguesa, um dos principais alvos marxistas, proclamado no Manifesto Comunista. Desarmem-se dos subterfúgios. Assumam suas reais intenções ... podemos ver as claras intenções desse grupo de ideólogos: doutrinar as crianças a todas essas práticas sexuais. Não se trata de discutir relações de gênero. Trata-se de erotizar crianças e estimular práticas sexuais das mais diversas ainda na infância. (Ramos, 2016, s.p., grifos meus)

Habitamos um Estado laico, pressuposto assegurado constitucionalmente, no qual a liberdade religiosa afronta os pressupostos da educação democrática e ataca severamente os anseios de uma educação pautada nos princípios 
democráticos de acesso universal com finalidade de pôr fim às diferenças sociais existentes no Brasil há séculos. É preciso reiterar que a livre manifestação do pensamento e a construção de um projeto em que seja possível produzir intenções de equidade entre mulheres e homens não estão travando uma batalha que visa a destruição da família cristã. O que se deseja é, em primeira instância, a justiça social.

As imagens a seguir são representações veiculadas como "memes" nas redes sociais. Promovem analogias desumanizantes, ferindo a liberdade de expressão e os princípios constitucionais. Promovem discursos de ódio formulados à docência ${ }^{12}$ mais do que à classe política.

Figura 2 - Ataque ao bordão petista "Pátria Educadora"

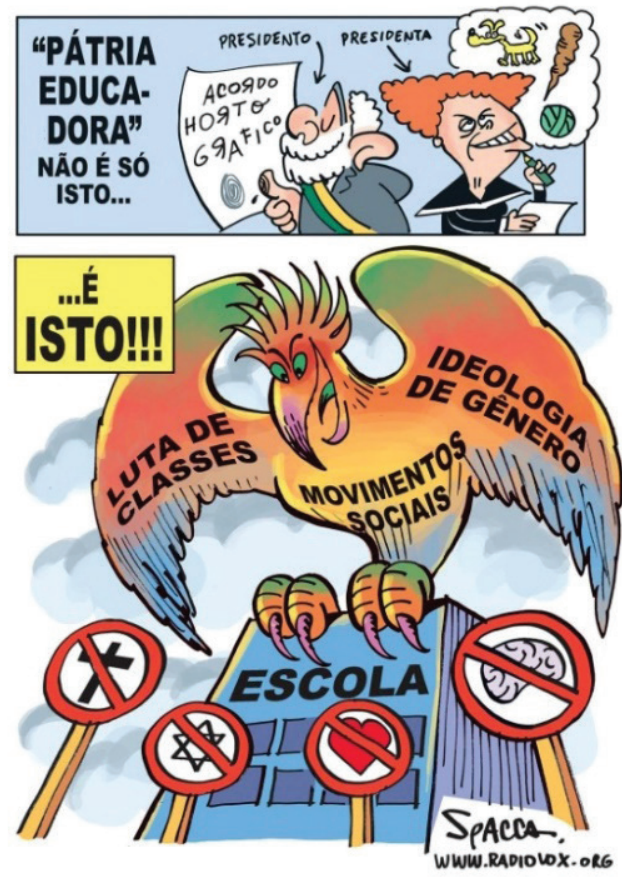

Fonte: https://liberdadeparaensinar.wordpress.com/tag/odio-aos-professores/ 
Figura 3 - Doutrinação Marxista na Educação

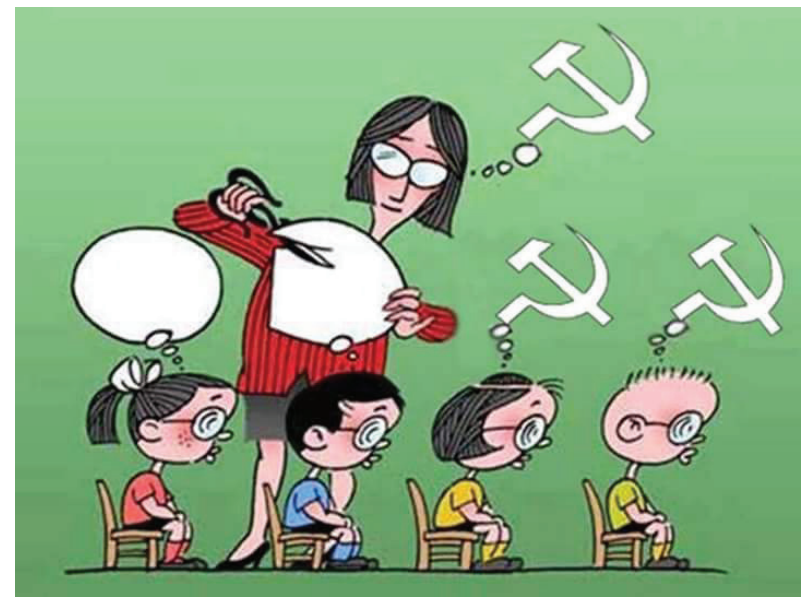

Fonte: https://liberdadeparaensinar.wordpress.com/tag/odio-aos-professores/

Figura 4 - orientação sexual vomitada em aluno

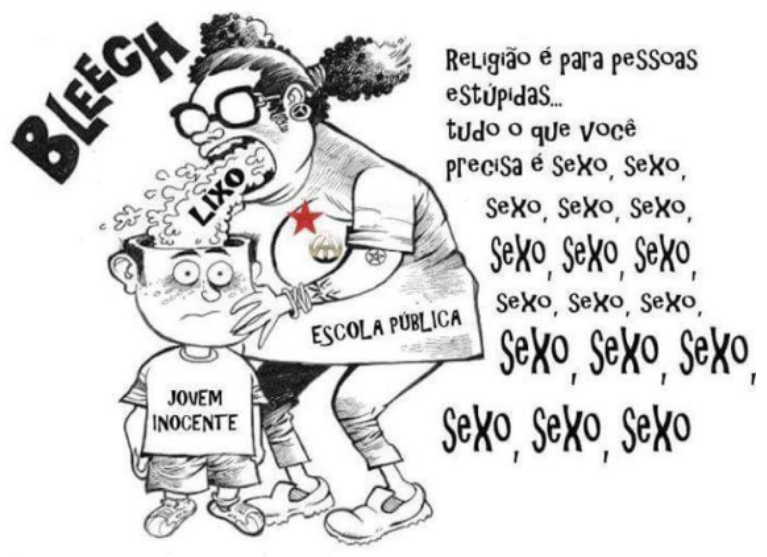

Fonte: https://liberdadeparaensinar.wordpress.com/tag/odio-aos-professores/

Essas representações, em seu conjunto, desvirtuam a concepção de terminologias existentes no campo da educação, política e filosofia ao passo que caracterizam os alunos como coisas. Nas Figuras 3 e 4 os vemos como receptáculos de uma lavagem cerebral, na medida em que as figuras das educadoras 
são visíveis ameaças. Percebe-se que não se denunciam nas imagens críticas às teorias que sofrem seus ataques. A escola é tida como instituição corruptora. O exercício que essas imagens propõem é a injúria aos trabalhadores da educação, bem como aos legítimos referenciais teóricos e aos movimentos sociais. Ao ler as imagens, o professor Fernando Penna destaca que "os olhos das professoras não aparecem, ocultos pelos seus óculos, reforçando a sua desumanização", e acrescenta:

Estes movimentos afirmam que a "ideologia de gênero" teria como meta incentivar os alunos a abandonar a religião e incentivá-los a fazer sexo. Discutir gênero em sala de aula não é isso. É problematizar a violência doméstica. É trazer para a sala de aula a representação de famílias de diferentes configurações. É permitir que as pessoas de diferentes orientações sexuais se percebam representadas, e não silenciadas, no conhecimento produzido nas escolas. (Penna, 2015, s.p.)

Supor que há doutrinação é também julgar que os estudantes não teriam capacidade para analisar de forma crítica e debater as relações de gênero na escola. No interior da sala de aula é possível perceber a ampla diversidade de posicionamentos éticos, políticos e sexuais. A dinâmica das aulas é fomentada por questões que, muitas vezes, partem dos anseios dos alunos e não do que está nos materiais impressos ou na abordagem dos professores.

Assim, entende-se que a sexualidade nos alunos não pode ser negada ou reprimida, precisa ser debatida, problematizada, de modo que os alunos se percebam como sujeitos que conhecem a si mesmos e têm controle sobre seus corpos. Falar de sexualidade ${ }^{13}$ significa empoderá-los frente a riscos a que estão expostos rotineiramente na vida em sociedade e, em casos mais específicos, nas relações que desenvolvem na internet.

Fernando Penna (2017) analisa que para o MESP as concepções de secularização da educação estão atreladas ao neotecnicismo, averiguando que a desqualificação do professor, acrescida de estratégias discursivas fascistas, está presente nos discursos produzidos pelos idealizadores do MESP, sobretudo por Miguel Nagib, criador e articulador do referido projeto. Para Penna, o advogado Nagib usa, não em vão, um recorte temporal de 30 anos para atacar o sistema educacional brasileiro: "O recorte não é casual, e eles [MESP] insistem nesse recorte em vários momentos: 30 anos, grosso modo, é o período da nossa redemocratização" (Penna, 2017, p.43). Pensar que esse grupo aspira a 
uma neutralidade em educação que antecede os últimos 30 anos da política brasileira é crer, indubitavelmente, que se está defendendo um projeto que vai além de uma "Escola Sem Partido", que por trás desse slogan pretende-se gerar uma consciência ingênua não crítica e não política. Despolitizar a escola equivaleria a concordar na produção de seres (alunos e professores) desprovidos de consciência crítica, facilmente manipuláveis.

Moura (2016) entende que os PCNs para o ensino fundamental, elaborados entre 1995 e 1997, representaram um avanço no que diz respeito à inserção das discussões de gênero no campo educacional. Entretanto, a autora pondera que essa inserção não se deu na área das Ciências Humanas e Sociais, pois nada existe sequer na parte dedicada à história. A inclusão se deu exclusivamente em ciências biológicas, por meio das recomendações de temas transversais.

Fernanda Moura afirma ainda que "a palavra gênero apareceu, mas em nenhum momento foi explicada, deixando-a aberta a interpretações várias, inclusive ao entendimento de gênero como um sinônimo de sexo" (p.116). Ela acrescenta que

Nos Parâmetros Curriculares para o ensino médio, a situação é talvez pior: a palavra gênero aparece uma única vez, na seção de História, em uma discussão sobre a cidadania no Brasil. Novamente, surge sem uma explicação do seu significado e podendo ser substituída por sexo, mantendo-se o sentido do texto. Entretanto, há, ao longo das recomendações, uma preocupação com a "pluralidade de sujeitos" e com as identidades individuais e coletivas, especificamente as de grupos minoritários entendendo as mulheres como um destes grupos ... Se o avanço no campo da história das mulheres e da história das relações de gênero não se faz presente nos parâmetros curriculares, também muito pouco se faz nos livros e materiais didáticos. (Moura, 2016, p.116)

O ensino de história foi e continua (hoje com mais força) afetado por essa tendência que negligencia as referidas abordagens aqui discutidas, na medida em que essas discussões, ao se alicerçarem sobre bases ideológicas, impedem o avanço das temáticas de gênero no campo educacional, ferindo o direito à diferença e o respeito ao outro, limitando a visão da plena democracia e chegando ao extremo de condená-la.

Os estudos de gênero vêm sendo escamoteados por essa expressão conservadora, tornando-se, a partir de determinados discursos, uma ameaça à 
sociedade, quando se pretende a percepção de quão plurais (e desiguais) são as sociedades. O contexto educacional não tem escapado a essas incoerências que tendem à negação do espaço escolar como ambiente de compreensão das diferenças sociais e de combate às formas de preconceito, entre suas muitas outras funções.

Uma reflexão bastante simples pode surgir quando os estudiosos e simpatizantes do gênero são vistos como agentes destruidores das famílias tradicionais. A questão que surge dessa máxima (destruição da família) que se disseminou nos discursos conservadores é esta: "Haveria nas escolas um único tipo de família (Furlani, 2003) associado aos seus alunos?" "Os alunos de uma escola são todos integrantes de uma família composta de pai, mãe, irmão?” "Não haveria nas centenas de escolas filhos de mães solteiras, mãe viúva, casada/amasiada pela segunda vez, com filhos agregados de famílias distintas?" Isso sem levar em conta a existência das famílias homoafetivas - cuja negação também é combatida pelos estudos de gênero. Se faz oportuna a noção de que a família, instituição incontestavelmente rígida, está também em constante transformação.

A partir dos estudos de Moura (2016, p.4), entende-se que os projetos do tipo Escola Sem Partido funcionam no campo da educação como "mecanismos de contenção que agem ... contra os avanços da laicidade do Estado e da secularização da cultura”. Assim, o que se teme na educação e, em boa medida, no ensino de história é a construção de uma efetiva política de igualdade dos sexos. O que os idealizadores dessas "campanhas" não perceberam é que no gênero não se nega o diferente, almeja-se a igualdade na diferença.

É oportuno, nestas considerações finais, recorrer às afirmações de Vera Corrêa (1995, p.47) em texto que versa sobre a formação político-pedagógica do professor da educação básica. A autora constata que passados 10 anos da redemocratização (visto que ela escreve em 1995), as relações entre as forças que atuam sobre a educação são complexas e causam a maioria dos problemas observados:

O sucesso ou o fracasso de uma proposta educacional se relacionam com forças que fogem a seu alcance. No entanto, essas mesmas forças tecem o tipo de sociedade que temos e dentro dela o tipo de escola, o que torna essa questão de grande relevância. Os problemas educacionais não podem ser discutidos buscando-se as 
suas raízes apenas no campo pedagógico, mas na teia de relações que se estabelecem no campo social mais amplo do contexto histórico-social onde a escola está inserida. (Corrêa, 1995, p.48-49)

Daí percebe-se quão fundamental se faz a reflexão sobre as potencialidades do professor na construção de uma educação não engessada por propostas políticas unilaterais. Aceitar sem resistência tais propostas representaria estar de acordo com a falência das conquistas viabilizadas pelas políticas públicas pós-governos militares. Para tanto, é preciso lutar diariamente contra a opressão encravada na bandeira do Movimento Escola Sem Partido.

\section{REFERÊNCIAS}

BRASIL. Presidência da República. Lei 9.394/1996. Estabelece as diretrizes e bases da educação nacional. (LDB). 20 dez. 1996. Disponível em: http://www.planalto.gov. br/ccivil_03/leis/L9394.htm; acesso em: 10 jul. 2017.

BRASIL. Secretaria de Educação Fundamental. Parâmetros Curriculares Nacionais Orientação Sexual. Brasília: MEC/SEF, v.10, 1997. Disponível em: http://portal. mec.gov.br/seb/arquivos/pdf/orientacao.pdf; acesso em: 13 jul. 2017.

CÂMARA DOS DEPUTADOS. Projeto de Lei 867/2015. Inclui, entre as diretrizes e bases da educação nacional, o "Programa Escola sem Partido" - Apensado ao PL 7180/2014. Brasília: 23 mar. 2015. Disponível em: http://www.camara.gov.br/proposicoesWeb/prop_mostrarintegra? codteor $=1230836 \&$ filename $=P L+7180 / 2014$; acesso em: 13 jul. 2017.

CAVALCANTE, Paulo; MATTOS, Yllan de. Quem é o doutrinador? 2016. Disponível em: http://www.vermelho.org.br/noticia/289907-1; acesso em: 13 jul. 2017.

CORRÊA, Vera. A formação político-pedagógica do professor: desafios da escola básica. Revista ADVIR, Rio de Janeiro: Associação de Docentes da Universidade Estadual do Rio de Janeiro, n.5, p.46-50, abr. 1995.

FIGUEIRÓ, Mary Neide D. A viabilidade dos Temas Transversais à luz da questão do trabalho docente. PSI - Revista de Psicologia Social e Institucional, Londrina, v.2, n.1, jun. 2000. Disponível em: http://www.uel.br/ccb/psicologia/revista/textov2n12.htm; acesso em: 12 jul. 2017.

FREIRE, Paulo. Pedagogia do oprimido. 60.ed. Rio de Janeiro: Paz \&Terra, 2014.

FURLANI, Jimena. Educação sexual: possibilidades didáticas. In: LOURO, Guacira L.; NECKEL, Jane F.; GOELLNER, Silvana V. (Org.) Corpo, gênero e sexualidade: um debate contemporâneo em educação. Petrópolis: Vozes, 2003. 
GENTILI, Pablo (Org.) Pedagogia da exclusão: o neoliberalismo e a crise da escola pública. Petrópolis: Vozes, 1995.

GENTILI, Pablo; SILVA, Tomaz T. da (Org.) Neoliberalismo, qualidade total e educação: visões críticas. Petrópolis: Vozes, 2001.

MIGUEL, Luis Felipe. Da "doutrinação marxista” à "ideologia de gênero": Escola Sem Partido e as leis da mordaça no parlamento brasileiro. Direito e Práxis, Rio de Janeiro, v.7, n.15, 2016. Disponível em: http://www.e-publicacoes.uerj.br/index. php/revistaceaju/article/view/25163; acesso em: 20 jul. 2017.

MOURA, Fernanda P. de. "Escola Sem Partido": relações entre Estado, educação e religião e os impactos no Ensino de História. Dissertação (Mestrado Profissional em Ensino de História) - Instituto de História, Universidade Federal do Rio de Janeiro (UFRJ). Rio de Janeiro, 2016.

PATEMAN, Carole. O contrato sexual. Trad. Marta Avancini. Rio de Janeiro: Paz e Terra, 1993.

PENNA, Fernando de A. O Escola Sem Partido como chave de leitura do fenômeno educacional. In: FRIGOTTO, Gaudêncio (Org.) Escola Sem Partido: esfinge que ameaça a educação e a sociedade brasileira. Rio de janeiro: Ed. Uerj, 2017.

O ódio aos professores. [s.l.], 18 set. 2015. Disponível em: https://liberdadeparaensinar.wordpress.com/2015/09/18/o-odio-aos-professores/ ; acesso em: 29 jun. 2017.

. O ódio aos professores se profissionaliza. [s.l.], 14 nov. 2016. Disponível em: https://professorescontraoescolasempartido.wordpress.com/2016/11/14/o-odio-aos-professores-se-profissionaliza; acesso em: 29 jun. 2017.

RAMOS, Sandra Lima de V. Não se combate o que não existe. Ideologia de gênero: contra fatos não há argumentos. Jornal Capital das Nascentes, Santa Catarina, dez. 2016. Disponível em: http://jornalaw.com.br/2016/12/10/fala-a-professora/; acesso em: 30 jun. 2017.

SCALA, Jorge. Ideologia de gênero: neototalitarismo e a morte da família. São Paulo: Katechesis, 2011.

TOKARNIA, Mariana. MEC retira termo "orientação sexual" da versão final da Base Curricular. Agência Brasil EBC: Brasília, abr. 2017. Disponível em: http://agenciabrasil.ebc.com.br/educacao/noticia/2017-04/mec-retira-termo-orientacao-sexual-da-versao-final-da-base-curricular; acesso em: 20 jul. 2017.

\section{NOTAS}

${ }^{1}$ Séculos após a Reforma Protestante, que tornou reais os projetos de Igrejas cristãs como a Luterana, Anglicana, Metodista, Presbiteriana e Batista, surge em 1901, nos Estados Unidos, 
o formato de cristãos e de Igrejas com legenda pentecostal, representada por nomenclaturas como Assembleia de Deus, Congregação Cristã no Brasil e Deus é Amor, entre outras. Mais recentemente apresentaram-se as chamadas denominações neopentecostais, como Universal do Reino de Deus, Igreja Internacional da Graça de Deus, Sara Nossa Terra etc.

${ }^{2}$ É importante destacar que depois desse, inúmeros projetos de lei do tipo "Escola Sem Partido" foram criados a partir de 2014, nos âmbitos estadual e municipal.

${ }^{3}$ Não pretendo apresentar teses novas, mas desnudar a inviabilidade desses projetos com base em estudos existentes nos campos da educação, das relações de gênero e da legislação educacional.

${ }^{4}$ Acrescento que a Constituição Federal prevê o direito a filiações partidárias a qualquer cidadão brasileiro.

${ }^{5}$ Quero destacar que a sala de aula é um importante espaço que permite aos alunos um ensaio para sua formação crítica e política, ao serem fomentadas discussões de ordem política.

${ }^{6}$ Entendo que a doutrinação existe na educação quando os professores são intimidados a explicar alguns conteúdos, sobretudo o da origem da espécie, num embate teológico-científico em que o desconforto em boa parte da categoria é notável. Opta-se muitas vezes por negligenciar a temática, impossibilitando o debate e a reflexão. Um claro exemplo da "educação bancária" problematizada pelo pensador Paulo Freire, ao verificar um modelo de ensino em que apenas se deposita teoria nos alunos, sem a sistematização e reflexão.

${ }^{7}$ Não posso deixar de mencionar um lamentável episódio envolvendo um dos ícones políticos, defensores do MESP e integrante do que estou caracterizando como reacionário, o deputado federal pelo estado do Rio de Janeiro, Jair Bolsonaro, que se tornou réu em ação do STF por incitar o crime de estupro e cometer injúria contra a deputada Maria do Rosário em 2014.

${ }^{8}$ Cf. trabalhos de MAYER (2016), ROTHBARD (2006), NOZICK (1974) e FREEMAN (2002).

${ }^{9}$ Reproduzo aqui nota de rodapé do texto citado: o website do MESP possui vários textos destinados a atacar o educador. Um deles é ilustrado com uma charge que afirma que seu método transforma "analfabetos inocentes em analfabetos comunistas" (DINIZ FILHO, s.d.); outro o acusa de plagiador (VIEIRA, s.d.). Em debate num canal de televisão, em julho de 2016, o criador do MESP, Miguel Nagib, causou espanto ao dizer que o objetivo do método Paulo Freire é recrutar jovens para o PT, aparentemente desconhecendo o fato de que as principais contribuições do educador pernambucano datam dos anos 1960, isto é, muito antes do surgimento do partido (MIGUEL, 2016, p.601).

${ }^{10}$ Tal acepção parece ser, em última análise, uma defesa ao neoliberalismo, que se abstém da interferência na economia e nos serviços a sociedade, mas, nas palavras de MIGUEL (2016), pretende regular fortemente a vida privada.

${ }^{11}$ Em virtude das demandas dos educadores com suas próprias disciplinas, por exemplo. 
${ }^{12}$ Os grifos em itálico são de PENNA, 2017. O mesmo autor analisa esses e outros memes veiculados em texto cuja referência encontra-se ao final deste trabalho.

${ }^{13}$ Observa-se que tanto a temática da sexualidade como a da ideologia de gênero estão circunscritas nos projetos "Escola Sem Partido".

Artigo recebido em 31 de agosto de 2017. Aprovado em 10 de setembro de 2018. 